\title{
Determinantes da criminalidade na região sudeste do Brasil: uma aplicação de painel espacial
}

\section{Determinants of criminality in the southeastern region of Brazil: A space panel application}

\author{
Otoniel Rodrigues Dos Anjos-Júnior* \\ Stélio Cô̂lho Lombardi-Filho ${ }^{* *}$ \\ Pedro Vasconcelos-Maia Do Amaral ${ }^{* *}$
}

\begin{abstract}
The goal of this study is to identify the main factors responsible for criminality in the southeast region of Brazil. To this end, a panel data structure was set up to monitor the evolution of crime in the southeast microregions. Global and local spatial autocorrelation tests were carried out together with the estimation of econometric spatial panel models. The results pointed to the existence of spatial dependence on crime rates in all the analyzed years. It was found that population density, GDP per capita, unemployment rate, and proportion of young people have a positive impact on homicide rates, which is relevant to understanding the phenomenon of crime.
\end{abstract}

Keywords: Criminality, southeast region, spatial panel.

\section{Resumo}

O objetivo desse estudo é identificar os principais fatores responsáveis pela criminalidade na regiâo Sudeste do Brasil. Para este fim, construiu-se um painel acompanhando a evolução da criminalidade nas microrregiôes sudestinas. Realizou-se testes de autocorrelação espacial global e local, juntamente com a estimação de modelos econométricos de painel espacial. Os resultados apontaram para a existência de dependência espacial das taxas de crime em todos os anos analisados. Identificou-se que a densidade populacional, o PIB per capita, a taxa de desemprego e a proporçấo de jovens impactam positivamente nas taxas de homicídios, sendo relevantes para a compreensão do fenômeno da criminalidade.

Palavras-chave: criminalidade, região sudeste; painel espacial.

*Universidade Federal da Paraíba, correo-e: pbdosanjos@hotmail.com

**Universidade Federal de Minas Gerais, correos-e: stelio.filho@hotmail.com; pedrovma@ ufmg.br 


\section{Introdução}

As mortes por homicídio e violência coletiva representam cerca de $10 \%$ das mortes globais relacionadas com lesóes, sendo que apenas em 2012 foram 475,000 assassinatos registrados no mundo. Entre as vítimas, $80 \%$ são homens, com 65\% destes com idade entre 15 e 49 anos. Julga-se que o acesso à armas de fogo fomenta fortemente essa mortalidade homicida no mundo, com aproximadamente metade de todos os casos cometidos. No Brasil, foram registrados 50,108 casos de homicídios em 2012, representando uma taxa de 32.4 por 100 mil habitantes, e aproximadamente $10 \%$ das mortes ocorridas no mundo. A taxa de mortalidade brasileira o coloca à frente de países como Equador (13.8), Peru (11), Paraguai (9.7), Argentina (6), Chile (4.6), Cuba (5), México (22), entre outros. Ao redor do mundo é possível encontrar taxas de homicídios por 100 mil habitantes expressivamente baixas em paises como Canadá (1.8), Espanha 0.8), Itália (0.9), França (1) e Japão (0.4) (OMS, 2016).

Os elevados índices de criminalidade observados no Brasil têm ganhado destaque na mídia nacional e internacional nos últimos anos. Waiselfisz (2013) mostra que, no Brasil, somente no ano de 2012, foram roubados 193,306 carros, 1,749 instituiçóes financeiras e 13,614 cargas. Além desses, também se registrou 51,101 estupros, 47,094 homicídios dolosos (praticado com intenção de matar) e 1,806 latrocínios (roubo seguido de morte). Considerando apenas a classificação de Crimes Violentos Letais Intencionais $(\mathrm{CVLI})^{1}$, observa-se para o Brasil um valor superior a $50 \mathrm{mil}$ casos neste mesmo ano. Apenas entre 2010 e 2012, os casos de CVLI's aumentaram $15.73 \%$. Por sua vez, as lesóes corporais culposas ocasionadas no trânsito $(326,823)$, somadas às outras lesóes corporais culposas $(24,996)$ e às lesóes corporais dolosas $(750,842)$, totalizam mais de um milhão de casos em 2012. Tais resultados são ainda mais preocupantes quando considerado as subnotificaçóes e os casos omissos.

As discussões acerca das motivações responsáveis pela criminalidade no Brasil são várias. Nesta perspectiva, encontram-se justificativas que atribuem a presente situação de insegurança do país a fatores como impunidade (fragilidade das leis ou benevolência das penas), baixo número de prisôes (as polícias prendem pouco) e prisóes que estimulam a prática de outros delitos (as prisóes que não recuperam).

O Escritório das Nações Unidas sobre Drogas e Crimes (United Nations Office on Drugs and Crime, UNODC) afirma que os principais fatores de risco para o crime e a vitimização estão relacionados à densidade

${ }^{1}$ CVLI engloba as seguintes categorias: homicídio doloso, latrocínio e lesão corporal seguida de morte. 
populacional e às disparidades de renda. Assim, o rápido crescimento populacional em áreas urbanas, juntamente com a migração de populaçóes rurais, podem se tornar fatores de risco se a capacidade de infraestrutura e o desenvolvimento social e econômico náo forem capazes de acompanhar tal crescimento.

Nesta linha, vários estudos empíricos têm mostrado a relação entre urbanização e criminalidade. Cano e Santos (2000), por exemplo, mostram que lugares mais urbanizados desencadeiam menores probabilidades de identificação e prisão dos criminosos, aumentando as possibilidades de fuga e a impunidade. A urbanizaçáo, associada à densidade populacional e à falta de estrutura básica, seria forte facilitador à prática criminosa (Fajnzylber et al., 2002b; Kume, 2004; Santos e Kassouf, 2008).

A concentração de renda é um dos pilares de sustentação dos altos índices de criminalidade observados no Brasil (Costa e Balestreri, 2010). Ehrlich (1975) aponta que o nível de renda, o desemprego e a educação surtem efeito sobre a escolha dos agentes pelo crime ou não crime ao longo da vida. Já Chiricos (1987) e Freeman (1994) acreditam existir relação positiva entre crime e desemprego, tornando o mercado de trabalho um elemento de fundamental importância para explicar o comportamento criminoso. Outros estudos também encontraram evidências de associação entre o desemprego e à criminalidade (Donohue e Levitt, 2001; Machin e Meghir, 2004).

Diversas pesquisas, tais como Andrade e Lisboa (2000), Fernandez e Pereira (2001) e Mendonça (2001) apontam que maiores salários resultam em menores taxas de criminalidade. No entanto, tais resultados não são consensuais e têm sofrido duras críticas. Por outro lado, a concentração de renda tem sido apontada por vários estudos como um importante determinante do crime (Fajnzylber et al., 2002a; Fajnzylber et al., 2002b; Cerqueira e Lobão, 2003b). Desse modo, há fortes evidências de associação positiva entre a desigualdade de renda e criminalidade.

Salienta-se, ainda, a relação entre o baixo nível de escolaridade dos agentes e o fenômeno da criminalidade (Imrohoroglu et al., 2000). Em outra perspectiva, os trabalhos de Wolpin (1978), Freeman (1994), Araujo Jr e Fajnzylber (2001), Gould et al. (2002) mostram a relação entre crime e dissuasão policial, demografia e mercado de trabalho.

A Organização Mundial da Saúde (OMS) tem classificado a violência brasileira como epidêmica ${ }^{2}$, o que ressalta a urgência pela implementação de políticas públicas visando a redução de tais índices. Conforme apontado

\footnotetext{
${ }^{2}$ Conforme o citado órgão internacional, as taxas de homicídios superiores a 10 por grupo de 100 mil habitantes são classificadas como epidêmicas. As taxas de mortalidade homicida do Brasil [2010 (22.7), 2011(25.0) e 2012 (25.8)] são claramente superiores aos encontrados no receituário da OMS.
} 
por Waiselfisz (2012), entre 2000 e 2010 houve aumento da violência na maior parte das regiōes do país: Norte (147.1\%), Nordeste (96.1\%), Sul (67.6\%) e Centro-Oeste (24\%). Todavia, a região Sudeste surpreendeu, apresentando redução de $42.4 \%$ nas suas taxas de violência neste decênio. Tal fenômeno merece atenção, sobretudo, porque esta redução foi influenciada por estados como Rio de Janeiro e São Paulo, que registraram queda na violência de $43.3 \%$ e $67.5 \%$, respectivamente (figura 1). É importante lembrar que estes estados estavam, até poucos anos, entre os de maior crescimento da violência e da criminalidade de modo geral.

Considerando a reduçáo observada nas taxas de criminalidade do Sudeste na última década, nota-se que é possível caminhar no sentido inverso e implementar políticas que são capazes de surtir efeito sobre os índices de criminalidade. No presente contexto, tem-se diversos estudos (Mocan, 2003; Zaverucha, 2004; Velásquez, 2004; Cerqueira et al., 2007; Sapori, 2007; Soares, 2008; Kahn e Zanetic, 2009) sugerindo medidas de combate e controle da criminalidade via implementação de políticas públicas de segurança para, ao menos no curto prazo, conter o avanço da violência.

Diante do exposto, nota-se que a criminalidade brasileira apresenta índices alarmantes, cujas razóes devem ser identificadas de modo a tornar possível a implementação de políticas públicas eficazes. Como visto, as taxas de criminalidade aumentaram em praticamente todas as regiôes do país, com exceção do Sudeste brasileiro. Sendo assim, este artigo se propóe a identificar os principais fatores responsáveis pela criminalidade nesta região. Para tanto, será construído um painel acompanhando a evolução

Figura 1

Evolução do número de mortes por homicídios na regiáo Sudeste (2003-2012)

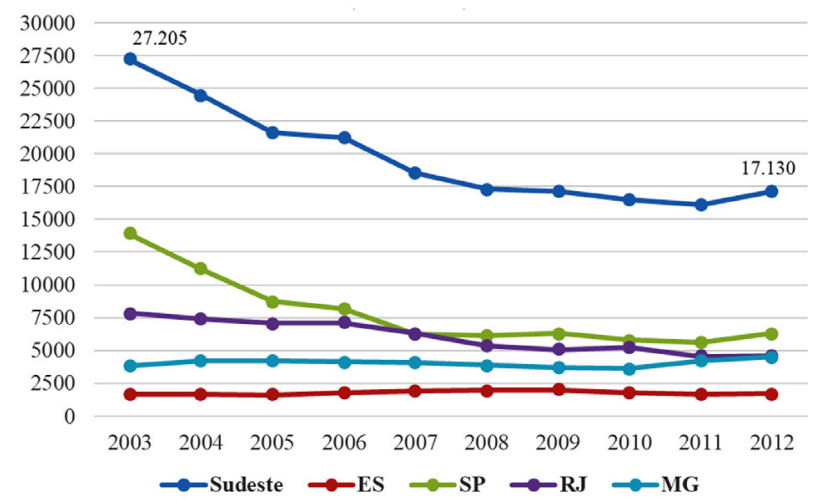

Fonte: elaboraçấo dos autores a partir dos dados do SIM-DATASUS (2017). 
da criminalidade ao longo dos anos e a estimação de modelos econométricos adequados para levar em consideração os efeitos de transbordamentos espaciais.

Este estudo se justifica pela importância que o Sudeste apresenta no contexto nacional. Apesar de ser a segunda menor região do país, é também a mais desenvolvida economicamente, sendo responsável por mais da metade do Produto Interno Bruto (PIB) nacional. Entender os determinantes das taxas de crime nesta regiâo auxilia na compreensão da dinâmica criminal do país, permitindo combater de modo mais eficaz suas consequências sobre a atividade econômica e o bem-estar da população.

Além desta introdução, este artigo é composto por mais quatro seções. A próxima seção, a contextualização teórica, discute brevemente as diferentes abordagens empregadas nos estudos de economia do crime. Em seguida, na terceira seção, serão apresentados os procedimentos metodológicos empregados na pesquisa. A quarta seção discute os resultados encontrados, enquanto que a quinta e última parte do estudo consiste em tecer as consideraçóes finais.

\section{Contextualização teórica}

A ação criminosa pode ser vista por diferentes óticas da ciência e, consequentemente, um mesmo fato acaba tendo diversas interpretaçóes. Cano e Soares (2002) relatam que existem teorias dispostas a explicar o comportamento criminoso considerando as patologias individuais, a deficiência do sistema social, a perda de controle, a desorganização social, e fatores situacionais ou de oportunidade.

Neste contexto, percebe-se algumas diferenças entre as teorias existentes para analisar o fenômeno da criminalidade, pois enquanto umas consideram o crime como sendo fruto do sistema e da sociedade como um todo (Governo, família e comunidade), outras evidenciam que o indivíduo possui o poder de decisão entre praticar ou não determinado ato ilícito, o que confere à criminalidade um caráter passível de análise microeconômica comportamental. Desse modo, devido as diversidades analíticas construídas ao longo dos anos, entender os fatores capazes de explicar a taxa de crime de um determinado ambiente pode ser tarefa bastante complicada e muitas vezes contraditória.

Shaw e MacKay (1942), ao estudarem a criminalidade, encontram que existem diferenças entre as taxas de crimes observadas nas áreas projetadas (que apresentam maior grau de infraestrutura) e as observadas nas periferias. Assim, nas áreas mais organizadas a taxa de criminalidade é 
relativamente menor que as constatadas nos ambientes dominados pela desorganização e falta de infraestrutura. Para Cerqueira e Lobão (2004), tal teoria foi denominada de Desorganização Social, e apontam a criminalidade como fruto do Status socioeconômico, mobilidade residencial, desagregação familiar entre outras.

Sutherland (1973), Matsueda (1982), Bruinsma (1992) e McCarthy (1996) analisaram como o comportamento dos indivíduos acerca do crime pode ser influenciado a partir de seus respectivos grupos de amizade e família. Tal teoria foi denominada de Aprendizado Social e postula que as situaçóes vivenciadas podem ser reflexo das experiências pessoais de cada agente com relaçáo a situaçóes de conflitos. Estas podem ser afetadas pelo grau de supervisão familiar, grupos de amizades, amigos com problemas com a polícia, contato com técnicas criminosas, entre outros (Cerqueira e Lobão, 2004).

A Teoria do Controle Social aplicada por diversos autores (Agnew, 1991; Agnew e White, 1992; Junger-Tas, 1992) aponta motivaçóes pelas quais alguns agentes não entram no mundo do crime. Neste caso, o enfoque é dado aos agentes que se abstêm do cometimento do crime, sendo tal fato influenciado pelas normas vigentes, as crenças, a percepção, o envolvimento do cidadáo no sistema social, entre outros fatores. Segundo Cerqueira e Lobão (2004), tal teoria afirma que quanto maior o envolvimento do cidadáo e seu elo com a sociedade, menor será a probabilidade deste se tornar um criminoso.

Outra importante teoria acerca do estudo da criminalidade foi denominada de Autocontrole. Esta considera que alguns agentes não foram capazes de desenvolver mecanismos psicológicos de autocontrole. Na ótica de Cerqueira e Lobão (2004), as distorçôes observadas no processo de socialização, ocasionados pela falta de imposição e de limites, faz com que o agente tome suas decisóes ao sabor do momento sem medir consequências. Esta teoria foi desenvolvida por Gottfredson e Hirschi (1990), sendo acompanhada por vários estudos que buscaram encontrar as causas que melhor explicam as taxas de crime de determinado ambiente (Gibbs et al., 1998; Arneklev et al., 1993; Polakowski, 1994).

Nota-se que os estudos da criminalidade podem ser vistos por diferentes ângulos. Uma relevante contribuição às pesquisas relacionadas à criminalidade foi construída por Becker (1968). Em seu trabalho seminal, este aponta que a decisão pelo crime é tomada racionalmente com base nos custos e benefícios da ação. Tal teoria foi intitulada de abordagem da Escolha Racional, pois argumenta que o indivíduo é capaz de tomar decisóes entre mercado legal e ilegal baseado no lucro líquido de cada um destes setores. Destaca-se que a partir da introdução da racionalidade aos estudos da criminalidade foi possível avançar e encontrar resultados 
baseados em instrumentos matemáticos e estatísticos (Fernandez e Pereira, 2001).

O agente otimizador descrito por Becker (1968) representa um caso clássico de maximização de ganhos esperados sujeito a perdas associadas a cada tomada de decisão individual. Portanto, tal teoria do crime apresenta oportunidades de otimização de ganhos, funcionando como setas indicativas de onde cada indivíduo deverá implementar maior dedicação. Fernandez e Santo (2008) mostram que a atividade criminosa possibilita, inclusive, encontrar uma curva de oferta de crimes apenas partindo do processo de maximizaçáo de lucro dos agentes envolvidos no processo de escolha entre crime e não crime.

McKenzie e Tullock (1975) apontam que o fato dos agentes serem racionais permite que a quantidade de crime de uma localidade seja determinada como qualquer outra atividade da economia. Assim, deve-se considerar que os indivíduos reagem a incentivos e podem praticar maior ou menor quantidade de crimes, pois tal fenômeno passa a depender essencialmente do comportamento marginal dos ganhos de cada setor em análise. Fernandez e Santo (2008) entendem que a teoria da Escolha Racional considera o setor criminal como uma forma de atividade econômica.

Apesar das críticas sofridas, sobretudo pelos adeptos das correntes sociológicas, a teoria da Escolha Racional tem sido testada empiricamente (Ehrlich, 1973; Heineke, 1978; Messner, 1982; Grogger, 1991; Almeida et al., 2005). Os resultados sugerem a existência de relação entre crime e economia. Cerqueira e Lobão (2004) apontam algumas variáveis que tem sido utilizada pelos adeptos da teoria da Escolha Racional, tais como salários, renda familiar per capita, desigualdade da renda, acesso a programas de bem-estar social, eficiência da polícia, adensamento populacional, magnitude das punições, inércia criminal, aprendizado social e educação.

\section{Metodologia}

Esta seção discute os procedimentos metodológicos empregados nesse estudo. Inicialmente, serão apresentadas as variáveis selecionadas para compor a base de dados, juntamente com uma justificativa teórica para a inclusão das mesmas. Em seguida, será discutida de forma sucinta a estratégia empírica adotada. Esta consiste na realização da análise exploratória de dados espaciais e na estimação de modelos econométricos que considerem a dependência espacial associada ao fenômeno da criminalidade.

A econometria espacial se diferencia da econometria tradicional por considerar efeitos espaciais na estimação e nos testes de hipótese. $\mathrm{Na}$ 
modelagem espacial é possível incorporar padróes de interação socioeconômica e determinadas características estruturais do sistema que está sendo avaliado (Anselin, 1988). Nesse contexto, verifica-se que o fenômeno da criminalidade já tem sido analisado a partir da ótica da econometria espacial (Almeida, 2007; Sartoris, 2000, Uchôa e Menezes, 2012). Há fortes argumentos em favor da adequabilidade dos modelos espaciais às análises de dados de crime em virtude, sobretudo, do tipo de banco de dados encontrado.

\subsection{Fonte e tratamento dos dados}

O objetivo desse estudo é identificar os determinantes da criminalidade na regiáo Sudeste do Brasil, levando em conta a distribuição espacial do fenômeno e o provável efeito de transbordamento consequente. Para este fim, construiu-se uma base de dados contemplando informaçóes socioeconômicas e demográficas das 160 microrregióes do Sudeste ${ }^{3}$, seguindo o que a literatura tem apontado como fatores associados à criminalidade (e.g. Cerqueira e Lobão, 2004; Santos e Kassouf, 2008; Uchôa e Menezes, 2012). Os dados levantados referem-se ao período 2003-2012, permitindo acompanhar a evolução da criminalidade ao longo de 10 anos.

A tabela 1 apresenta a descrição das variáveis da pesquisa, juntamente com as estatísticas descritivas. A variável de interesse, a criminalidade, será representada nesse estudo pelo número de homicídios por 100 mil habitantes em cada microrregião. Estas informações encontram-se disponíveis na base de dados do Sistema de Informaçôes de Mortalidade (SIM-DATASUS, 2017).

Em relação às variáveis explicativas, a densidade populacional, medida pela razão entre o número de pessoas residentes no município e a sua área total, tem por objetivo identificar se microrregiōes com maior concentração territorial estáo associadas a taxas de homicídios mais elevadas.

Vem sendo frequentemente apontado pela literatura que quanto maior o percentual de pessoas residentes em áreas urbanas numa dada localidade, maior serão seus índices de criminalidade (e.g. Araujo Jr e Fajnzylber, 2001; Mendonça, 2002; Peixoto, 2003; Kume, 2004; Oliveira, 2005; Santos e Kassouf, 2008). De fato, a violência é um fenômeno que se mostra de maneira mais intensa em áreas urbanas, em decorrência da concentração de pessoas, renda e serviços. Ademais, conforme Cano e Santos (2000), ambientes mais urbanizados reduzem as chances de iden-

\footnotetext{
${ }^{3}$ Os dados discretos são agrupados em espaços limitados: bairros, municípios, microrregiões, mesorregiões, estados, dentre outros. Cabe lembrar que essa limitação possibilita surgir o problema da Unidade Espacial Modificável, em que a delimitação e a escala das unidades espaciais podem afetar os resultados das análises (Openshaw, 1984).
} 
tificação e prisão dos criminosos. Nesta ótica, Glaeser e Sacerdote (1999) apontam que a prática criminosa é facilitada nos grandes centros urbanos devido as menores probabilidades de identificação do agressor. Para Glaeser et al. (1996), o fenômeno da urbanização facilita a relação de grupos criminosos, melhora o aprendizado do crime e facilita a toca de informaçôes. Por estas razóes, incluiu-se no estudo a variável taxa de urbanizaçãó .

\section{Tabela 1}

Descrição das variáveis da pesquisa

\begin{tabular}{lrrrrl}
\hline \multicolumn{1}{c}{ Variável } & \multicolumn{1}{c}{ Média } & $\begin{array}{c}\text { Desvio-Pa- } \\
\text { drāo }\end{array}$ & \multicolumn{1}{c}{ Mínimo } & Máximo & Fonte \\
\hline $\begin{array}{l}\text { Homicídios por 100 mil } \\
\text { habitantes }\end{array}$ & 16.1708 & 13.3300 & 0.0000 & 92.2192 & DATASUS \\
Densidade populacional & 177.2137 & 567.9414 & 4.5298 & $5.940,1470$ & IBGE \\
PIB per capita & $14.836,9400$ & $10.707,9000$ & $2.108,8040$ & $149.125,2000$ & IPEADATA \\
Taxa de desemprego & 8.8430 & 1.9479 & 5.8000 & 13.0000 & DATASUS \\
Coeficiente de Gini & 0.5190 & 0.0211 & 0.4850 & 0.5600 & IPEADATA \\
Taxa de urbanização & 90.0422 & 5.4498 & 80.7000 & 97.4000 & IBGE \\
Proporçăo de homens & 49.8057 & 0.8225 & 47.2940 & 52.2864 & DATASUS \\
Proporçáo de jovens & 26.3474 & 1.4701 & 21.9557 & 30.2708 & DATASUS \\
Taxa de analfabetismo & 6.7417 & 2.3073 & 3.6700 & 11.0600 & DATASUS \\
Número de observaçōes & 1.600 & & & & \\
\hline
\end{tabular}

Fonte: elaboraçáo dos autores a partir dos dados do IPEADATA (2017), IBGE (2017) e DATASUS (2017).

O Produto Interno Bruto per capita da microrregiáo foi utilizado como um indicador de nível de atividade econômica e desenvolvimento de cada localidade ${ }^{5}$. Essa variável é bastante utilizada em trabalhos aplicados no âmbito da economia do crime (Andrade e Lisboa, 2000; Fernandez e Pereira, 2001; Mendonça, 2001). Entretanto, não há consenso acerca do sinal esperado, pois acredita-se que este pode divergir conforme a modalidade de crime ${ }^{6}$ (Araujo Jr e Fajnzylber, 2001; Piquet e Fajnzylber, 2001).

Tão importante quanto se considerar o montante da renda é verificar como esta se encontra distribuída entre os habitantes. Sendo assim, o coeficiente de Gini referente a cada estado do Sudeste foi usado como

\footnotetext{
${ }^{4}$ Como a série histórica desta variável encontra-se disponível apenas a nível estadual, não foi possível desagregar por microrregião.

${ }^{5}$ Os valores desta variável encontram-se deflacionados, sendo o ano base 2002.

${ }^{6}$ Existem variáveis que causam crimes contra a vida e outras que causam crimes patrimoniais. Enquanto a renda tem efeito positivo quando considerado os crimes patrimoniais, por outro, afeta negativamente os crimes contra a vida ou pessoas.
} 
regressor, em que a expectativa é que quanto pior for a distribuição de renda de um estado, maior será a criminalidade em suas microrregióes (Cano e Santos, 2000; Araujo Jr e Fajnzylber, 2000 e 2001; Andrade e Lisboa, 2001; Cerqueira e Lobão, 2003a).

Questôes educacionais e de oportunidades de emprego também costumam estar associados à criminalidade (Ehrlich, 1975; Fajnzylber et al., 2002a; Imrohoroglu et al., 2000). Níveis mais elevados de capital humano tornam os indivíduos trabalhadores mais produtivos e capazes de obter maiores retornos no mercado de trabalho, reduzindo as chances de que os mesmos recorram a uma vida de crimes. Além disso, maiores oportunidades de emprego reduzem a necessidade de se cometer crimes para adquirir os meios de subsistência. Dessa forma, a fim de mensurar como indicadores educacionais e do mercado de trabalho influenciam a criminalidade, as taxas de analfabetismo e desemprego dos estados foram consideradas nesta pesquisa.

Por fim, também se incluiu na análise a proporçáo de jovens e de homens na população. Conforme ressaltado por Uchôa e Menezes (2012), jovens são indivíduos em idade criminal ativa e os que mais sofrem com homicídios relacionados ao tráfico de drogas. Segundo Santos e Kassouf (2008), a maioria das vítimas de homicídios intencionais é jovem e do sexo masculino. Desse modo, a proporção de jovens entre 15 e 29 anos em cada estado, juntamente com a proporção de indivíduos do sexo masculino, foram utilizadas como variáveis explicativas.

Alguns estudos aplicados, tais como o de Uchôa e Menezes (2012), incluem como variáveis de controle o efetivo policial e as despesas com segurança pública. $\mathrm{O}$ problema com tal procedimento é a endogeneidade consequente. Se por um lado espera-se que um maior efetivo policial e maiores gastos com segurança reduzam a criminalidade, por outro é fácil imaginar que quanto maior a criminalidade, maiores serão os valores destas variáveis. Esta simultaneidade, se não tratada corretamente na estimação do modelo, resulta em estimativas inconsistentes. Por esta razão, optou-se nessa pesquisa por não considerar tais variáveis e assumir que as mesmas não estáo correlacionadas com os demais regressores incluídos, tornando o modelo livre de viés.

\subsection{Análise exploratória de dados espaciais}

Antes de realizar as estimativas dos modelos aqui propostos, apresenta-se uma análise exploratória das taxas de criminalidade. Com isso, objetiva-se analisar previamente a estrutura espacial dessa variável nas microrregiōes do Sudeste. A Análise Exploratória de Dados Espacial (AEDE) é um conjunto de técnicas que permite descrever e visualizar distribuições 
espaciais, identificar localizaçóes atípicas ou outliers espaciais, e detectar padrôes de associaçóes espaciais (clusters ou hot spots), sugerindo regimes ou outras formas de heterogeneidade espacial (Anselin, 1988; Anselin, 1999). A execução da AEDE pode ser efetuada a partir da utilização de medidas de avaliação globais e/ ou locais de autocorrelação espacial (Gallo e Ertur, 2000). Tais indicadores de autocorrelação podem ser representados através de testes formais de associação espacial, como as estatísticas I de Moran Global e I de Moran Local.

A estatística I de Moran pode ser utilizada na detecção da autocorrelação espacial global. Tal indicador pode ser representado por meio de um valor único representando o grau de associação espacial presente nos dados. Formalmente, o I de Moran Global pode ser expresso da seguinte forma:

$$
\boldsymbol{I}=\frac{N}{\sum_{i} \sum_{j} w_{i j}} \frac{\sum_{i} \sum_{j} w_{i j}\left(y_{i t}-\bar{y}_{t}\right)\left(y_{j t}-\bar{y}_{t}\right)}{\sum_{i}\left(y_{i t}-\bar{y}_{t}\right)^{2}}
$$

Em que $N$ é o número de regióes, $w_{i j}$ são os elementos da matriz de pesos espaciais $(W), y_{i t}$ é a observação na regiáo $i$ no período $t$ e $\bar{y}_{t}$ é a média das observaçóes entre as regiôes no período $t$. Conforme Anselin (1995), a matriz $W$ contempla as informações referentes à dependência espacial entre as $N$ regióes $i$. Os elementos $w_{i j}$ indicam a associação espacial entre as regiôes $i$ e $j$, sendo os elementos na diagonal principal iguais a zero.

A análise da autocorrelação espacial local, por sua vez, pode ser efetuada utilizando-se o I de Moran Local, que é um indicador do tipo LISA (Local Indicator of Spatial Association). Segundo Anselin (1995), o I de Moran Local fornece indicação de clusters ou agrupamentos espaciais significativos de valores semelhantes em torno de certa observaçáo. Neste contexto, o I de Moran Local para cada regiáo e período pode ser expresso por:

$$
\boldsymbol{I}_{i}=\frac{\left(y_{i t}-\bar{y}_{t}\right) \sum_{j} w_{i j}\left(y_{j t}-\bar{y}_{t}\right)}{m_{0}}
$$

Em que $m_{0}=\frac{\sum_{i}\left(y_{i t}-\bar{y}_{t}\right)^{2}}{N}$.

Sendo assim, conforme a equação (2), valores positivos de $I_{t}$ devem indicar presença de agrupamentos de valores similares entre si. Por outro, valores negativos indicam presença de agrupamentos de valores relativamente dissimilares. Destaca-se que o resultado do I de Moran Local é um mapa temático composto por cores distintas. Interpreta-se tais resultados considerando os seguintes tipos de associação espacial: i) os clusters Alto- 
-Alto, nos quais tem-se regióes que apresentam alto valor da variável em estudo circundadas por uma vizinhança em que o valor médio da mesma variável também é alto; ii) clusters Baixo-Baixo, nos quais tem-se regióes que apresentam baixo valor da variável em estudo circundadas por uma vizinhança em que o valor médio da mesma variável também é baixo; e iii) os outliers Baixo-Alto e Alto-Baixo. Neste contexto, a AEDE deve funcionar como ponto de apoio para a estimação econométrica, pois possibilita ex ante a constatação de indícios de autocorrelação espacial, sendo que tal fato é devidamente confirmado apenas a partir das estimaçôes dos modelos espaciais.

A análise dos indicadores global e local envolve a construção de uma matriz de pesos espaciais que determina as relaçóes de proximidade entre as unidades espaciais analisadas. De acordo com Golgher (2015), a matriz de pesos é usada na econometria espacial para descrever a estrutura de dependência entre as unidades em estudo. Neste artigo, tanto as análises estatísticas quanto as estimaçóes dos modelos espaciais serão realizadas considerando-se uma matriz de vizinhança de contiguidade do tipo Queen de primeira ordem, normalizada na linha. Almeida (2012) mostra que o critério de vizinhança baseado na contiguidade considera que duas regióes são vizinhas quando estas dividem uma fronteira física comum. Portanto, considera-se uma matriz binária de pesos espaciais $(\boldsymbol{W})$ que atribui valor para o caso em que dois municípios são vizinhos e valor no caso contrário.

\subsection{Abordagem Econométrica}

Para investigar a relação entre as taxas de criminalidade e as demais variáveis apresentadas neste trabalho, realiza-se a estimação de um modelo econométrico. A abordagem econométrica empregada nesse estudo consiste em utilizar métodos de painel espacial. Como se sabe, dados em painel é o termo usado para ser referir a qualquer base de dados na qual as mesmas unidades de corte transversal (nesse caso, as microrregióes do Sudeste) são acompanhadas ao longo do tempo. A utilização dessa estrutura de dados implica uma série de vantagens. Ao aumentar o tamanho da amostra, ela fornece uma base com maior variabilidade e menor colinearidade entre as variáveis. $\mathrm{O}$ aumento nos graus de liberdade torna a estimação mais eficiente, resultando em estimativas mais precisas e estatísticas de teste com maior poder. Também torna possível observar relaçôes dinâmicas e controlar a heterogeneidade não observada individual, assumida como constante no tempo e considerada um dos principais fatores de viés por variável omitida (Wooldridge, 2010; Elhorst, 2010). 
Seguindo Elhorst (2014), considere o modelo convencional para dados empilhados (pooled):

$$
y_{i t}=\boldsymbol{x}_{i t} \boldsymbol{\beta}+\mu_{i}+\varepsilon_{i t}, \quad i=1, \ldots, N \text { e } t=1, \ldots, T
$$

Em que: $\boldsymbol{y}_{i t}$ é a observação da variável dependente $i$ no tempo $t ; \boldsymbol{x}_{i t}$ é um vetor de variáveis explicativas; $\boldsymbol{\beta}$ é o vetor de parâmetros desconhecidos a ser estimado; $\mu_{i}$ é o efeito espacial individual; e $\varepsilon_{i t}$ é o termo de erro aleatório independente e identicamente distribuído, com média 0 e variância constante $\left(\sigma^{2}\right)$. Ao incorporar o efeito espacial, $\mu_{i}$, o modelo passa a controlar por todos os efeitos espaciais específicos de cada unidade, que são invariantes no tempo e cuja omissão poderia ocasionar viés nas estimativas (Elhorst, 2010).

Assumindo uma matriz de pesos espaciais $(\boldsymbol{W})$ constante no tempo e um painel balanceado, é possível especificar efeitos de interação espacial entre as unidades. A inclusão da variável dependente espacialmente defasada resulta no modelo de lag espacial:

$$
y_{i t}=\delta \sum_{j=1}^{N} w_{i j} y_{j t}+\boldsymbol{x}_{i t} \boldsymbol{\beta}+\mu_{i}+\varepsilon_{i t}
$$

Em que $\delta$ é o parâmetro espacial autorregressivo e $w_{i j}$ um elemento de $\boldsymbol{W}$. Desse modo, para o caso dessa pesquisa, esse modelo considera que o número de homicídios em uma dada microrregiáo é conjuntamente determinado com o número de homicídios das microrregióes vizinhas.

Se por outro lado a interaçáo espacial se manifesta na forma de erros espacialmente correlacionados, então tem-se o modelo de erro espacial:

$$
\begin{gathered}
y_{i t}=\boldsymbol{x}_{\boldsymbol{i}} \boldsymbol{\beta}+\mu_{i}+u_{i t} \\
u_{i t}=\lambda \sum_{j=1}^{N} w_{i j} u_{i t}+\varepsilon_{i t}
\end{gathered}
$$

Em que $u_{i t}$ representa o termo de erro espacialmente autocorrelacionado e $\lambda$ é o coeficiente de autocorrelação espacial. De acordo com Anselin et al. (2008), o modelo de erro espacial não requer um modelo teórico 
para a especificação da interação espacial, sendo um caso especial de uma matriz de covariância de erros não esféricos.

Uma das formas de lidar com os efeitos espaciais específicos é trata-los como efeitos fixos. Nesse caso, tais efeitos podem ser excluídos ao se estimar o modelo em termos de desvios em relação à média temporal das varáveis, o que é numericamente igual à inclusão de uma dummy para cada unidade (Wooldridge, 2010).

Fazendo $y_{i t}^{*}=y_{i t}-\frac{1}{T} \sum_{t=1}^{T} y_{i t}, x_{i t}^{*}=x_{i t}-\frac{1}{T} \sum_{t=1}^{T} x_{i t}$ e $\varepsilon_{i t}^{*}=\varepsilon_{i t}-\frac{1}{T} \sum_{t=1}^{T} \varepsilon_{i t}, \quad$ o modelo de lag espacial com efeitos fixos pode ser estimado por Máxima Verossimilhança (MV), no qual o log da função de verossimilhança concentrada a ser maximizada é dada por:

$\log L=-\frac{N T}{2} \log \left(2 \pi \sigma^{2}\right)+T \log \left|\boldsymbol{I}_{N}-\delta \boldsymbol{W}\right|-\frac{1}{2 \sigma^{2}} \sum_{i=1}^{N} \sum_{t=1}^{T}\left(y_{i t}^{*}-\delta\left[\sum_{j=1}^{N} w_{i j} y_{j t}\right]^{*}-\boldsymbol{x}_{i t}^{*} \boldsymbol{\beta}\right)^{2}$

Em que $\boldsymbol{I}_{N}$ é uma matriz identidade de dimensão $N \times N$ e “*” denota desvios em relação à média. Como pode ser observado pela equação (6), o estimador de MV leva em conta a endogeneidade decorrente da inclusão do termo $\sum_{j} w_{i j} y_{j t}$.

O modelo de erro espacial com efeitos fixos, por sua vez, também pode ser estimado por MV. Nesse caso, o log da função e verossimilhança assume a seguinte forma:

$L o g L=-\frac{N T}{2} \log \left(2 \pi \sigma^{2}\right)+T \log \left|I_{N}-\lambda W\right|-\frac{1}{2 \sigma^{2}} \sum_{i=1}^{N} \Sigma_{t=1}^{T}\left\{y_{i t}^{*}-\lambda\left[\sum_{j=1}^{N} w_{i j} y_{j t}\right]^{*}-\left(x_{i t}^{*}-\lambda\left[\sum_{j=1}^{N} w_{i j} x_{j t}\right]^{*}\right) \boldsymbol{\beta}\right\}^{2}$

Se por outro lado os efeitos espaciais são considerados parâmetros aleatórios não observáveis, supostamente não correlacionados com os regressores, então tem-se um modelo de efeitos aleatórios. Nesse caso, o $\log$ da função de verossimilhança do modelo de lag com efeitos aleatórios passa a ser:

$$
\log L=-\frac{N T}{2} \log \left(2 \pi \sigma^{2}\right)+T \log \left|\mathbf{I}_{N}-\delta \boldsymbol{W}\right|+\frac{N}{2} \log \phi^{2}-\frac{1}{2 \sigma^{2}} \sum_{i=1}^{N} \sum_{t=1}^{T}\left(y_{i t}^{*}-\delta\left[\sum_{j=1}^{N} w_{i j} y_{j t}\right]^{\cdot}-x_{i t}^{*} \beta\right)^{2}
$$

Em que e $y_{i t}^{*}=y_{i t}-(1-\phi) \frac{1}{T} \sum_{t=1}^{T} y_{i t}$ e $\boldsymbol{x}_{i t}^{*}=\boldsymbol{x}_{i t}-(1-\phi) \frac{1}{T} \sum_{t=1}^{T} \boldsymbol{x}_{\boldsymbol{i t}}$, sendo $\phi$ os pesos associados aos componentes de corte transversal dos dados, com 0 $\leq \phi^{2}=\frac{\sigma^{2}}{\left(T \sigma_{\mu}^{2}+\sigma^{2}\right)} \leq 1$ (Elhorst, 2014).

Por fim, tem-se a estimaçáo do modelo de erro espacial com efeitos aleatórios. A estimação deste modelo é mais complexa do que os demais modelos apresentados até o momento ${ }^{7}$, sendo o $\log$ da função de verossimilhança expresso por:

\footnotetext{
${ }^{7}$ Para maiores detalhes ver Elhorst (2014), Anselin et al. (2008) e Millo e Piras (2012).
} 


$$
\begin{aligned}
\log L= & -\frac{N T}{2} \log \left(2 \pi \sigma^{2}\right)-\frac{1}{2} \log |\boldsymbol{V}|+(T-1) \sum_{i=1}^{N} \log |\boldsymbol{B}|-\frac{1}{2 \sigma^{2}} \boldsymbol{e}^{T}\left(\frac{1}{T} \boldsymbol{\iota}_{T} \boldsymbol{\iota}_{T}^{T} \otimes \boldsymbol{V}^{-1}\right) \boldsymbol{e}- \\
& \frac{1}{2 \sigma^{2}} \boldsymbol{e}^{T}\left(\boldsymbol{I}_{T}-\frac{1}{T} \boldsymbol{\iota}_{T} \boldsymbol{\iota}_{T}^{T}\right) \otimes\left(\boldsymbol{B}^{\boldsymbol{T}} \boldsymbol{B}\right) \boldsymbol{e}
\end{aligned}
$$

Em que $\boldsymbol{V}=\boldsymbol{T} \varphi \boldsymbol{I}_{N}+\left(\boldsymbol{B}^{\boldsymbol{T}} \boldsymbol{B}\right)^{-1}, B=\boldsymbol{I}_{N}-\lambda \boldsymbol{W}$ e $\boldsymbol{e}=\boldsymbol{Y}-\boldsymbol{X} \boldsymbol{\beta}$.

A escolha entre qual modelo usar, lag ou erro espacial, pode ser feita com base na teoria econômica ou testes de especificação. Já a escolha entre efeitos fixos e aleatórios segue a literatura econométrica sobre modelos de dados em painel. Conforme Wooldridge (2010), quando algumas variáveis explicativas não variam muito no tempo, o estimador de efeitos fixos pode resultar em estimativas imprecisas. Nesse caso, é preciso recorrer ao modelo de efeitos aleatórios para que se possa obter boas estimativas dos parâmetros populacionais. Além disso, se de fato o modelo de feitos aleatórios for apropriado, então seus estimadores serão mais eficientes, pois terão variância menor.

Enfim, a especificação do modelo de regressão a ser estimado neste artigo é a seguinte:

Homicídios $_{i t}=\log \left(\right.$ Dens.pop $\left._{i t}\right)+\log ($ PIB per capita $)+\log \left(\right.$ Desemp $\left._{i t}\right)+$ $\log \left(\right.$ Gini $\left._{i t}\right)+\log \left(\right.$ Urb $\left._{i t}\right)+\log \left(\right.$ Homens $\left._{i t}\right)+\log \left(\right.$ Jovens $\left._{i t}\right)+\log \left(\right.$ Analf $\left._{i t}\right)+\mu_{i}+\varepsilon_{i t}$

Em que a descrição das variáveis é a mesma reportada na tabela 1. A variável dependente, número de homicídios por 100 mil habitantes, encontra-se em nível, enquanto que as variáveis explicativas serão incorporadas ao modelo com valores em logaritmo natural.

\section{Resultados}

Nesta seção serão descritos os resultados da pesquisa. Inicialmente, serão reportados os resultados da análise exploratória. Em seguida, discute-se os resultados dos modelos econométricos.

\subsection{Resultados da AEDE}

O quadro 1 reporta os resultados da AEDE realizada por meio do diagrama de dispersão do I de Moran Global e pelo LISA Univariado da taxa de criminalidade observada nas microrregióes do Sudeste, entre 2003 e $2012^{8}$.

\footnotetext{
${ }^{8}$ Os mapas temáticos obtidos a partir do LISA são compostos por cinco cores distintas, cada qual representando um tipo de associação espacial: Vermelha (Alto-Alto), Azul (Baixo-Baixo), Cinza (Baixo-Alto), Rosa (Alto-Baixo) e Branca (Não Significativo).
} 
Tais indicadores apontam se há indícios de autocorrelação espacial agindo sobre os dados. Para tanto, conforme enunciado anteriormente, considerou-se uma matriz de contiguidade espacial do tipo Queen de primeira ordem, normalizada na linha.

Os quadrantes do I de Moran Global são: Q1 (Alto-Alto, AA), Q2 (Alto-Baixo, AB), Q3 (Baixo-Baixo, BB) e Q4 (Baixo-Alto, BA). Realizando-se um teste de hipótese via 999 permutaçóes dos valores do I de Moran Global, é possível rejeitar, a 1\% de pseudo-significância, a hipótese nula de aleatoriedade espacial em todos os períodos considerados. Dessa forma, essa estatística aponta indícios de dependência espacial da criminalidade.

Para Anselin (1995) o indicador de associação espacial global pode ocultar ou mesmo ser insatisfatório na identificação de padrốes espaciais locais. Sendo assim, tem-se que tanto os clusters quanto os outliers espaciais podem ser camuflados frente aos indicadores globais de autocorrelação espacial. Diante de tais circunstâncias, torna-se fundamental a estimação de um indicador LISA'. Como documentado por Anselin (1995), o citado indicador de associação espacial possibilita capturar localmente possíveis padrôes de autocorrelaçáo espacial, identificando agrupamentos de objetos com valores de atributos semelhantes entre si.

Nota-se que o resultado apresentado pelo LISA (quadro 1) é capaz de confirmar localmente a incidência de autocorrelação espacial já constatada por meio do indicador global. Portanto, tem-se que a autocorrelaçáo espacial vigente na taxa de criminalidade foi comprovada tanto global quanto localmente, sendo um forte indício para se acreditar em uma distribuição espacial não aleatória desse fenômeno na região Sudeste.

Seguindo os resultados apresentados pelo LISA entre 2003 e 2012, observa-se que, dentre as microrregiōes que apresentaram autocorrelação espacial em sua taxa de criminalidade, a maior parte (60\%) apresenta associaçáo do tipo Baixo-Baixo. $\mathrm{Na}$ sequência, encontram-se as microrregiōes que apresentaram associação do tipo Alto-Alto (32.58\%). Por sua vez, as relaçôes consideradas mais dissimilares entre si, os outliers espaciais, apresentaram representatividade relativamente menor: Baixo-Alto (5.07\%) e Alto-Baixo (3.38\%).

Destacando-se o comportamento dos clusters Alto-Alto e Baixo-Baixo ao longo dos anos, constata-se que as microrregióes que formam tais aglomerados tendem a ficar cada vez mais concentradas com o passar do tempo. Conforme os anos vão passando, tanto a relação Alto-Alto quanto a Baixo-Baixo mostram indícios de que seguem determinado processo de atração espacial, ficando cada vez mais próximos entre si. Nota-se, ainda,

${ }^{9}$ Neste artigo, o I de Moran Local. 
Quadro 1

Resumo das Estatísticas do I de Moran Global e do LISA entre 2003 e 2012

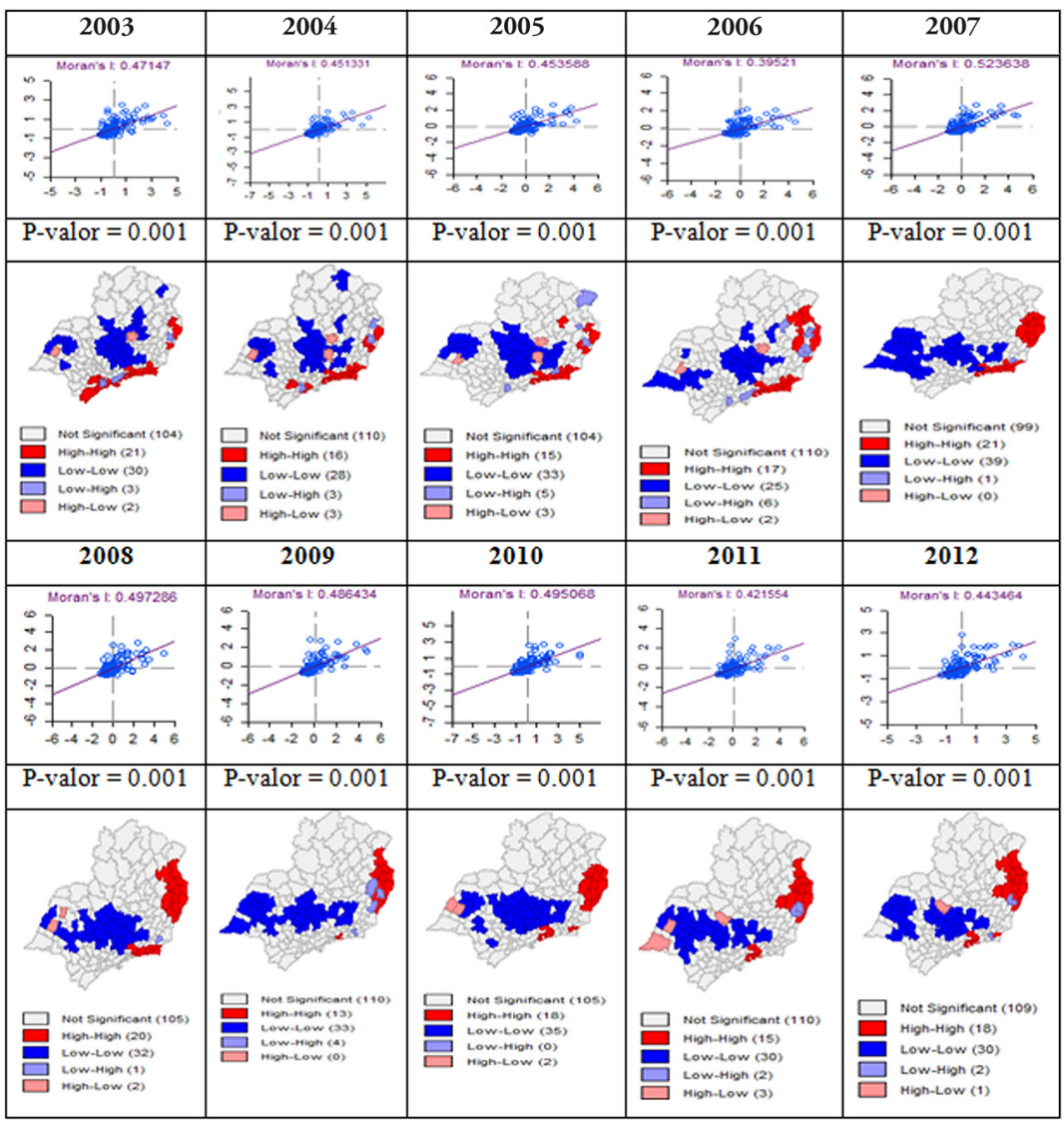

Fonte: elaboração dos autores a partir do software Geoda, desenvolvido por Anselin et al. (2006).

que as demais relaçóes (BA e $\mathrm{AB})$ não apresentam grande representatividade e se expressam sob a forma de pequenos grupos formados por pontos praticamente isolados ao longo dos anos.

\subsection{Resultados das estimaçóes dos modelos econométricos}

A tabela 2 apresenta os resultados das estimaçóes dos modelos tradicionais de dados em painel, ou seja, sem levar em conta a dependência espacial do crime entre as microrregióes. Uma vez que boa parte dos regressores varia muito pouco ao longo do tempo, inclusive pelo fato de alguns estarem disponíveis apenas a nível estadual, optou-se por considerar apenas os resultados do modelo de efeitos aleatórios. 
O modelo aponta para uma relação positiva entre a densidade populacional e a criminalidade. Mais especificamente, um aumento de $1 \%$ nesta variável implica em um aumento de 0.014 homicídios por $100 \mathrm{mil}$ habitantes. Os demais coeficientes estimados indicam um efeito positivo do PIB per capita, do desemprego e da proporçấo de jovens sobre os homicídios, tendo este último apresentado um valor bastante expressivo: um aumento de $1 \%$ na proporção de jovens resulta em aumento de 0.27 homicídios por 100 mil habitantes.

Tabela 2

Resultados das estimaçóes sem efeitos espaciais

\begin{tabular}{lcc}
\hline & \multicolumn{2}{c}{ Efeitos aleatórios } \\
\cline { 2 - 3 } & Coeficiente & Erro-Padrão \\
\hline (Densidade populacional) & $1.4022^{*}$ & 0.7187 \\
(PIB per capita) & $5.2190^{*}$ & 0.9806 \\
(Taxa de desemprego) & $8.3260^{*}$ & 1.6172 \\
(Coeficiente de Gini) & 2.5666 & 9.9218 \\
(Taxa de urbanização) & $-49.7751^{*}$ & 18.2858 \\
(Proporção de homens) & 25.4792 & 36.1364 \\
(Proporção de jovens) & $27.2983^{*}$ & 6.9128 \\
(Taxa de analfabetismo) & -5.1869 & 3.0922 \\
Intercepto & -10.2247 & 159.7162 \\
\hline
\end{tabular}

Nota: *p-valor $<0.05$.

Fonte: elaboraçáo dos autores a partir dos resultados da pesquisa.

Ao contrário do esperado, o coeficiente associado à taxa de urbanização apresentou sinal negativo. Apesar desse resultado aparentemente contraditório, é importante lembrar que a especificação desse modelo não leva em conta os efeitos espaciais de transbordamento da criminalidade. Por esta razão, estimou-se modelos de painel espacial adequados para tratar esse aspecto do fenômeno em estudo.

A tabela 3 contempla os resultados da estimação do modelo espacial de efeitos aleatórios. Como o coeficiente da lag espacial, , foi significativo em ambos os modelos, e como acredita-se haver um forte efeito contágio da criminalidade entre as microrregióes, não serão reportados os resultados dos modelos de erro espacial. O valor positivo de sugere, de fato, que há uma relação positiva entre a criminalidade de uma microrregiáo e a criminalidade das localidades vizinhas. Assim, um aumento na média de homicídios nas microrregióes vizinhas de resulta em um aumento dos homicídios nessa mesma região. 


\section{Tabela 3}

Resultados do modelo de lag espacial

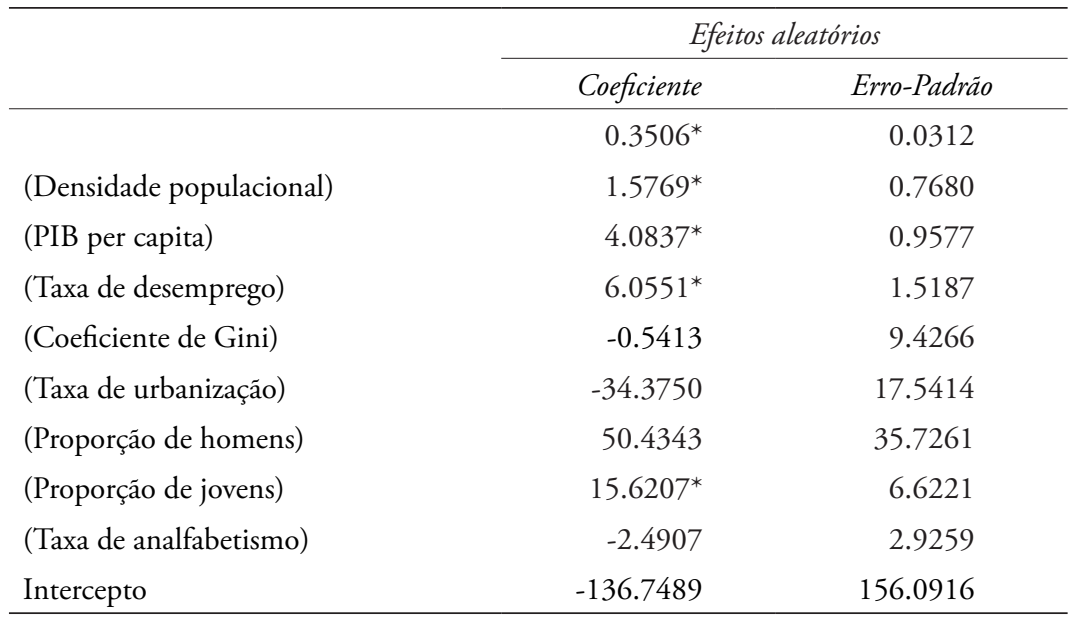

Nota: ${ }^{*}$ p-valor $<0,05$.

Fonte: elaboração dos autores a partir dos resultados da pesquisa.

Os coeficientes da tabela 3 representam os efeitos diretos das variáveis explicativas sobre a criminalidade no Sudeste brasileiro. Desse modo, observa-se que um aumento de $1 \%$ na densidade populacional tem um impacto direto de 0.0158 sobre a taxa de homicídios. Todavia, é possível também calcular qual é o efeito total dessa variável, por meio do seu efeito multiplicador ${ }^{10}:\left(\begin{array}{c}1 \\ 1-\delta\end{array}\right) \cdot \beta_{k}=\left(\frac{1}{1-0.3506}\right) \cdot 0.015769=0.0243$. Assim, este resultado corrobora alguns achados da literatura (Glaeser e Sacerdote, 1999; Kume, 2004; Uchôa e Menezes, 2012) de que um maior adensamento populacional favorece a ação criminosa.

Para a variável de PIB per capita, tem-se também uma relação positiva com a criminalidade. Sendo assim, um aumento de $1 \%$ neste regressor tem um efeito total de 0.0629 sobre a taxa de homicídios, de acordo com o modelo estimado. Tal resultado já era esperado, uma vez que quanto maior a renda e mais desenvolvida economicamente for uma regiáo, maiores tendem a ser seus índices de criminalidade.

A taxa de desemprego também apresentou coeficiente positivo e significativo no modelo espacial. Um aumento de $1 \%$ no desemprego resulta em um crescimento total de 0.0932 no número de homicídios por 100 mil habitantes. Conforme explicado anteriormente, menores oportunidades de emprego tendem a aumentar a necessidade de se cometer crimes.

${ }^{10} \mathrm{O}$ efeito total considera, além dos efeitos diretos, os efeitos de transbordamento entre as microrregióes. Por esta razáo, seu valor é tão maior quanto maior for o parâmetro de defasagem espacial.. 
Logo, é de se esperar que quanto maior o desemprego numa localidade, maior seja a ocorrência de ações criminosas.

O coeficiente da variável referente à proporção de jovens no estado sugere um efeito direto total bastante elevado, cerca de 0.2405 homicídios por mil habitantes. Tal resultado reforça os estudos que apontam esta variável demográfica como um importante preditor da ocorrência de crimes (Araujo Jr e Fajnzylber, 2000; Santos e Kassouf, 2008).

Por fim, vale ressaltar que os coeficientes das variáveis de analfabetismo, proporção de homens, índice de Gini e taxa de urbanização não foi significativo no modelo espacial. Apesar de alguns estudos terem encontrado evidências de efeitos significativos desses regressores, vale lembrar que poucos fizeram uso da estrutura de dados em painel. Além disso, a região Sudeste, foco desse estudo, é a segunda com menor taxa de analfabetismo ${ }^{11}$ e possui a mais elevada taxa de urbanização dentre as regióes brasileiras. Assim, não é surpreendente que estes fatores não tenham se mostrado relevantes para explicar a taxa de criminalidade nesta regiáo.

\section{Conclusáo}

Esse artigo teve como objetivo central identificar os principais fatores responsáveis pela criminalidade na regiâo Sudeste do Brasil. Conforme apontado, entre 2000 e 2010 as taxas de criminalidade aumentaram em praticamente todas as regiôes do país, à exceção do Sudeste. Tal resultado foi impulsionado pela queda acentuada das taxas de crime nos estados de São Paulo e Rio de Janeiro.

Em termos metodológicos, construiu-se um painel acompanhando a evolução da criminalidade na referida regiáo, entre os anos 2003 e 2012. Realizou-se testes de autocorrelação espacial global e local, juntamente com a estimação de modelos de painel espacial para identificar como certas variáveis influenciam o número de homicídios.

Os resultados dos testes de autocorrelação espacial, I de Moran Global e I de Moran Local, apontaram a existência de dependência espacial das taxas de crime, em todos os anos analisados. Assim, dentre as microrregiōes que apresentaram autocorrelação espacial em sua taxa de criminalidade, a maior parte (60\%) apresenta associação do tipo Baixo-Baixo. Em seguida, têm-se as microrregiôes que apresentaram associação do tipo Alto-Alto (32.58\%). Por sua vez, as relaçóes consideradas mais dissimilares entre si

${ }^{11}$ Atrás apenas da região Sul, segundo os dados da Pesquisa Nacional por Amostra de Domicílios (PNAD, 2012). 
apresentaram representatividade relativamente menor: Baixo-Alto (5.07\%) e Alto-Baixo (3.38\%).

Com relação aos resultados das estimaçóes, identificou-se que a densidade populacional, o PIB per capita, a taxa de desemprego e a proporção de jovens impactam positivamente as taxas de homicídios das microrregiōes sudestinas. Ao contrário do esperado, não foi encontrado efeito significativo das taxas de urbanização e analfabetismo, do índice de Gini e da proporção de homens.

Por fim, destaca-se que a partir dos resultados desse estudo foi possível constatar que os aspectos que afetam a criminalidade no Sudeste encontram-se relacionadas com variáveis socioeconômicas do espaço em análise. Sendo assim, as políticas públicas relativas ao controle da criminalidade devem ser elaboradas considerando tais características de cada localidade.

Como avanços futuros, sugere-se pesquisas que levem em conta a estrutura hierárquica dos dados de criminalidade, uma vez que muitas variáveis se encontram disponíveis apenas a nível estadual, enquanto que outras estão disponíveis a nível municipal. Outro avanço interessante seria a identificação de um instrumento adequado para as variáveis de efetivo policial e gastos com segurança pública. A utilização direta desses regressores, sem a instrumentalização, possivelmente resulta em estimativas viesadas devido à problemas de simultaneidade. Adicionalmente, seria interessante testar os efeitos da disseminação da criminalidade em outros espaços, tais como municípios e bairros. Tal processo permitiria observar se a criminalidade caminha da periferia para as áreas centrais, ou em sentido contrário.

\section{Referências}

Agnew, Robert (1991), "A longitudinal test of social control theory and delinquency", Journal of Research in Crime and Delinquency, 28 (2), Sage Publishing, Los Angeles, Estados Unidos do America, pp. 126-156.

Agnew, Robert e Helene Raskin White (1992), "An empirical test of general strain theory", Criminology, 30 (4), Wiley Online Library, Georgia, Estados Unidos do América, pp. 475-500.

Almeida, Eduardo (2012), Econometria espacial aplicada, Editora Alínea, Campinas, Brasil. 
Almeida, Marco Antônio Silveira de (2007), "Análise exploratória e modelo explicativo da criminalidade no Estado de São Paulo: interação espacial”, dissertação de mestrado, Universidade Estadual Paulista, São Paulo, Brasil.

Almeida, Eduardo, Eduardo Haddad e Geoffrey Hewings (2005), "The spatial pattern of crime in minas gerais: an exploratory analisys", Economia Aplicada, 9 (1), The University of São Paulo Regional and Urban Economics Lab, São Paulo, Brasil, pp. 1-27.

Andrade, Mônica Viegas e Marcos de Barros Lisboa (2000), "Desesperança de vida: homicídio em Minas Gerais, Rio de Janeiro e São Paulo: 1981 a 1997”, IX Seminário sobre a Economia Mineira, Universidade Federal de Minas Gerais, 29 de agosto e 1 de setembro, Minas Gerais, Brasil, pp. 775-808.

Andrade, Mônica Viegas e Marcos de Barros Lisboa (2001), "A economia da saúde no Brasil", in Marcos de Barros Lisboa e Naércio Aquino Menezes-Filho (orgs.), Microeconomia e sociedade no Brasil, Fundação Getulio Vargas, Rio de Janeiro, Brasil, pp. 285-332.

Anselin, Luc, Julie Le Gallo e Hubert Jayet (2008), "Spatial Panel Econometrics”, in László Mátyás e Patrick Sevestre (eds), The econometrics of Panel Data: fundamentals and recent developments in theory and practice, Springer, Berlin, Alemanha, pp. 625-660.

Anselin, Luc, Ibnu Syabri e Youngihn Kho (2006), "GeoDa: an Introduction to Spatial Data Analysis”, Geographical Analysis, 38 (1), University of California, Santa Barbara, California, Estados Unidos do America, pp. 5-22.

Anselin, Luc (1999), "Interactive techniques and exploratory Spatial Data Analysis", in Paul Longley, Michael Goodchild, David Maguire e Davie Rhind (eds.), New developments in Geographical Information Systems: principles, techniques, management and applications, University of California, Santa Barbara, California, Estados Unidos do America, pp. 253-266.

Anselin, Luc (1995), "Local Indicator of Spatial Association-LISA", Geographical Analysis, 27 (2), University of California, Santa Barbara, California, Estados Unidos do America, pp. 93-115. 
Anselin, Luc (1988), Spatial econometrics: methods and models, Kluwer Academic Publishers, University of California, Santa Barbara, Estados Unidos do America.

Araujo Jr, Ari Francisco e Pablo Fajnzylber (2001), "O que causa a criminalidade violenta no Brasil? Uma análise a partir do Modelo Econômico do Crime: 1981 a 1996”, working paper núm.162, Centro de Desenvolvimento e Planejamento Regional, Minas Gerais, Brasil.

Araujo Jr, Ari Francisco e Pablo Fajnzylber (2000), "Crime e economia: um estudo das microrregióes mineiras", Revista Econômica do Nordeste, 31, especial, Banco do Nordeste, Fortaleza, Brasil, pp. 630-659.

Arneklev, Bruce, Harold Grasmick, Charles Tittle e Robert Bursik (1993), "Low self-control and imprudent behavior", Journal of Quantitative Criminology, 9 (3), Springer, Berlin, Alemanha, pp. 225247.

Becker, Gary (1968), "Crime and punishment: an economic approach", Journal of Political Economy, 76, The University of Chicago Press Journals, Chicago, Estados Unidos do America, pp. 169-217.

Bruinsma, Gerben (1992), "Differential association theory reconsidered: an extension and its empirical test", Journal of Quantitative Criminology, 8 (1), Springer, Berlin, Alemanha, pp. 29-49.

Cano, Inácio e Gláucio Soares (2002), As teorias sobre as causas da criminalidade, Instituto de Pesquisa Econômica Aplicada, Rio de Janeiro, Brasil.

Cano, Inácio e Nilton Santos (2000), Violência letal, renda e desigualdade no Brasil, Instituto de Pesquisa Econômica Aplicada, Rio de Janeiro, Brasil.

Cerqueira, Daniel, Alexandre Carvalho, Waldir Lobão e Rute Rodrigues (2007), "Análise dos custos e consequências da violência no Brasil”, working paper núm. 1284, Instituto de Pesquisa Econômica Aplicada, Rio de Janeiro, Brasil. 
Cerqueira, Daniel e Waldir Lobão (2004), "Determinantes da criminalidade: arcabouços teóricos e resultados empíricos", DADOSRevista de Ciências Sociais, 47 (2), Instituto de Estudios Sociales y Políticos de la Universidad del Estado de Rio de Janeiro, Rio de Janeiro, Brasil, pp. 233-269.

Cerqueira, Daniel e Waldir Lobão (2003a), "Condições socioeconômicas, polícia e produção criminal”, working paper núm. 957, Instituto de Pesquisa Econômica Aplicada, Rio de Janeiro, Brasil.

Cerqueira, Daniel e Waldir Lobão (2003b), "Determinantes da Criminalidade: uma resenha dos modelos teóricos e resultados empíricos”, working paper núm. 0956, Instituto de Pesquisa Econômica Aplicada, Rio de Janeiro, Brasil.

Chiricos, Theodore (1987), "Rates of crime and unemployment: an analysis of aggregate research evidence", Social Problems, 34 (2), Oxford University Press, Oxford, Inglaterra, pp. 187-212.

Costa, Ivone e Ricardo Balestreri (orgs.) (2010), Segurança pública no Brasil: um campo de desafios, Editora da Universidade Federal da Bahia, Salvador, Brasil

DATASUS (Dados do Sistema Único de Saúde) (2017), "Ministério da Saúde”, DATASUS, Brasília, Brasil, <http://www2.datasus.gov. br/DATASUS/index.php?area=0206>, 10 de janeiro de 2017.

Donohue, John e Steven Levitt (2001), "The impact of legalized abortion on crime", Quarterly Journal of Economics, 116 (2), Harvard University Press, Massachusetts, Estados Unidos do America, pp. 379-420.

Ehrlich, Isaac (1975), "On the relation between education and crime", in Thomas Juster (ed.), Education, income and human behavior, McGraw-Hill, Nova Iorque, Estados Unidos do America, pp. 313-337.

Ehrlich, Isaac (1973), "Participation in illegitimate activities: a theoretical and empirical investigation", Journal of Political Economy, 81 (3), The University of Chicago Press, Chicago, Estados Unidos do America, pp. 521-565. 
Elhorst, Jean Paul (2014), Spatial econometrics: from cross-sectional data to spatial panels, Springer, Berlin, Alemanha.

Elhorst, Jean Paul (2010), "Spatial Panel Data Models", in Manfred Fischer e Arthur Getis (eds.), Handbook of applied spatial analysis: software tools, methods and applications, Springer, Berlin, Alemanha, pp. 377-408

Fajnzylber, Pablo, Daniel Lederman e Norman Loayza (2002a), "Inequality and violent crime", The Journal of Law and Economics, 45 (1), The University of Chicago Press Journals, Chicago, Estados Unidos do America, pp. 1-40.

Fajnzylber, Pablo, Daniel Lederman e Norman Loayza (2002b), "What causes violent crime?", European Economic Review, vol. 46, Elsevier, Washington, Estados Unidos do America, pp. 1323-1357.

Fernandez, José e Rogério Pereira (2001), "Diagnóstico da criminalidade na Bahia: uma análise a partir da Teoria Econômica do Crime”, Revista Econômica do Nordeste, núm. 32, Banco do Nordeste, Fortaleza, Brasil, pp.792-806.

Fernandez, José Carrera e Ana Priscila Espírito Santo (2008), "Criminalidade sob a ótica do presidiário: o caso da penitenciária Lemos Brito, na Bahia”, Revista Desenbahia, 4 (9), Governo da Bahia, Salvador, Brasil, pp. 233-258.

Freeman, Richard Barry (1994), "Crime and the job market", working paper núm. 4910, The National Bureau of Economic Research, Cambridge, Massachusetts, Estados Unidos do America.

Gallo, Julie e Cem Ertur (2000), "Exploratory spatial data analysis of the distribution of regional per capita GPD in Europe, 1980-1995”, Papers in Regional Science, 82 (2), Regional Science Association International (RSAI), Miláo, Itália, pp. 175-201.

Gibbs, John, Dennis Giever e Jamie Martin (1998), “Parental management and self-control: an empirical test of Gottfredson and Hirschi's general theory", Journal of Research in Crime and Delinquency, 35 (1), Sage Publishing, Los Angeles, Estados Unidos do America, pp. $40-70$. 
Glaeser, Edward e Bruce Sacerdote (1999), "Why is there more crime in cities?", Journal of Political Economy, 107 (6), The University of Chicago Press Journals, Chicago, Estados Unidos do America, pp. S225-S258.

Glaeser, Edward, Bruce Sacerdote e Jose Scheinkman (1996), "Crime and social interactions”, Quarterly Journal of Economics, 11 (1), Harvard University Press, Massachusetts, Estados Unidos do America, pp. 507-548.

Golgher, André Braz (2015), Introdução à Econometria Espacial, Paco Editorial, São Paulo, Brasil.

Gottfredson, Michael e Travis Hirschi (1990), A general theory of crime, Stanford University Press, Stanford, Estados Unidos do America.

Gould, Eric, Bruce Weinberg e David Mustard (2002), "Crime rates and local labor market opportunities in the United States: 19791997", The Review of Economics and Statistics, 84 (1), The MIT Press, Massachusetts, Estados Unidos do America, pp. 45-61.

Grogger, Jeffrey (1991), "Certainty vs. severity of punishment", Economic Inquiry, 29 (2), Western Economic Association International, Estados Unidos do America, pp. 297-309.

Heineke, John (1978), Economic models of criminal behavior, North-Holland, Amsterdã, Holanda.

IBGE (Instituto Brasileiro de Geografia e Estatística) (2017), "Estimativas de População", Editora do IBGE, Brasília, Brasil, <https:// www.ibge.gov.br/estatisticas-novoportal/sociais/populacao/ 9103-estimativas-de-populacao.html?\&t=downloads $>, 10 \mathrm{de}$ janeiro de 2017.

Imrohoroglu, Ayse, Antonio Merlo e Peter Rupert (2000), "On the political economy of income redistribution and crime", International Economic Review, 41 (1), Wiley, Pensilvânia, Estados Unidos do America, pp. 1-25.

IPEADATA (Instituto de Pesquisa Econômica Aplicada) (2017), Editora do Instituto de Pesquisa Econômica Aplicada, Rio de Janeiro, Brasil, <www.ipeadata.gov.br>, 10 de janeiro de 2017. 
Junger-Tas, Josine (1992), "An empirical test of social control theory", Journal of Quantitative Criminology, 8 (1), Springer, Berlin, Alemanha, pp. 9-28.

Kahn, Tulio e Zanetic, André (2009), "O papel dos municípios na segurança pública”, Coleção Segurança com Cidadania, vol. 2, Estudos criminológicos, Brasília, Brasil, pp. 83-126.

Kume, Leandro (2004), "Uma estimativa dos determinantes da taxa de criminalidade brasileira: uma aplicação em painel dinâmico", XXIII Encontro Nacional de Economia, 7 a 10 de dezembro de 2004, João Pessoa, Brasil.

Machin, Stephen e Costas Meghir (2004), "Crime and economic incentives", Journal of Human Resources, 39 (4), The University of Wisconsin Press, Wisconsin, Estados Unidos do America, pp. 958-979.

Matsueda, Ross (1982), “Testing control theory and differential association: a causal modeling approach", American Sociological Review, vol. 47, Sage Publishing, Los Angeles, Estados Unidos do America, pp. 489-504.

Mccarthy, Bill (1996), "The attitudes and actions of others: tutelage and sutherland's Theory of Differential Association”, British Journal of Criminology, 36 (1), Oxford Academic, Londres, Reino Unido, pp. 135-147.

Mckenzie, Richard e Gordon Tullock (1975), The new world of economics explorations: into the human experience, Homewood: Irwin, Alemanha.

Mendonça, Mário Jorge (2002), “Criminalidade e violência no Brasil: uma abordagem teórica e empírica", Revista Brasileira de Economia de Empresas, 2 (1), Universidade Católica de Brasília, Brasília, Brasil, pp. 33-49.

Mendonça, Mário Jorge (2001), Um modelo de criminalidade para o caso Brasileiro, Instituto de Pesquisa Econômica Aplicada, Rio de Janeiro, Brasil. 
Messner, Steven (1982), "Poverty, inequality, and the urban homicide rate: some unexpected findings", Criminology, 20 (1), Wiley Online Library, Geórgia, Estados Unidos do America, pp.103114.

Millo, Giovanni e Gianfranco Piras (2012), “SPLM: Spatial Panel Data Models in R", Journal of Statistical Software, 47 (1), American Statistical Association, Alexandria, Estados Unidos do America, pp. 1-38.

Mocan, Naci (2003), "Crime control: lessons from the New York city experience", Documento preparado para el Seminario internacional sobre prevención del delito y la violencia en entornos urbanos, Sistema unificado de información en violencia y delincuencia de la Subsecretaria de Gobierno de Bogotá (SUIVD), maio 2003, Bogotá, Colômbia.

Oliveira, Cristiano Aguiar (2005), "Criminalidade e o tamanho das cidades brasileiras: um enfoque da economia do crime", working paper núm. 14, Universidade de Passo Fundo, Passo Fundo, Brasil.

OMS (Organização Mundial da Saúde) (2016), "World health statistics 2016: monitoring health for the SDGs, sustainable development goals", OMS, Paris, França, <http://www.who.int/gho/publications/world_health_statistics/2016/en/>, 10 de janeiro de 2017.

Openshaw, Stan (1984), The modifiable areal unit problem (concepts and techniques in modern geography), Geo Books, Norwich, Inglaterra.

Peixoto, Betânia Totino (2003), "Determinantes da criminalidade no município de Belo Horizonte”. Belo Horizonte, dissertação de mestrado, Universidade de Minas Gerais-UFMG, Minas Gerais, Brasil.

Piquet, Leandro e Pablo Fajnzylber (2001), "La criminalidad en regiones metropolitanas de Rio de Janeiro y São Paulo: factores determinantes de la victimación y política pública”, in Pablo Fajnzylber, Daniel Lederman e Norman Loayza (orgs.), Crimen y violencia en America Latina, Banco Mundial-Alfaomega, Washington, Estados Unidos do America, pp. 197-235. 
PNAD (Pesquisa Nacional por Amostra de Domicílios) (2012), "Pesquisa Nacional por Amostra de Domicílios", Instituto Brasileiro de Geografia e Estatística, Brasília, Brasil, <https://ww2.ibge.gov.br/ home/estatistica/populacao/trabalhoerendimento/pnad2012/ default_sintese.shtm>, 15 de janeiro de 2017.

Polakowski, Michael (1994), "Linking self and social control with deviance: illuminating the structure underlying a general Theory of Crime and its relation to deviant activity", Journal of Quantitative Criminology, 10 (1), Springer, Berlin, Alemanha pp. 41-78.

Santos, Marcelo Justus e Ana Lúcia Kassouf (2008), "Estudos econômicos das causas da criminalidade no brasil: evidências e controvérsias", EconomiA, 9 (2), Associação Nacional dos Centros de Pós-Graduação em Economia, Brasília, Brasil, pp. 343-372.

Sapori, Luís Flávio, (2007), Segurança pública no Brasil: desafios e perspectivas, Editora FGV, Rio de Janeiro, Brasil.

Sartoris, Alexandre (2000), "Homicídios na cidade de São Paulo: uma análise da causalidade e autocorrelação espaço-temporal", tese doutorado, Universidade de São Paulo, São Paulo, Brasil.

Shaw, Clifford e Henry Donald Mckay (1942), juvenile delinquency and urban areas, University of Chicago Press, Chicago, Estados Unidos do America.

SIM-DATASUS (Sistema de Informaçóes sobre Mortalidade do Sistema Único de Saúde) (2017), "Óbitos por causas externas (X85-Y09)”, Ministério da Saúde, Brasília, Brasil, <http://tabnet.datasus.gov. br/cgi/tabcgi.exe?sim/cnv/ext10br.def>, 10 de janeiro de 2017.

Soares, Gláucio (2008), Não matarás: desenvolvimento, desigualdade e homicídios, Editora FGV, Rio de Janeiro, Brasil.

Sutherland, Edwin (1973), "Development of the theory", in Edwin Sutherland e Karl Schuessler (eds.), On analyzing crime, The University of Chicago Press, Chicago, Estados Unidos do America, pp. 30-41.

Uchôa, Carlos Frederico e Tatiana Almeida Menezes (2012), "Spillover espacial da criminalidade: Uma aplicação de Painel Espacial para os Estados Brasileiros", XL Encontro Nacional de Centro de 
Pós-Graduação em Economia, Porto de Galinhas, 11 e 14 de dezembro, Pernambuco, Brasil.

Velásquez, Hugo Acero (2004), "Os governos locais e a segurança cidadâ”, texto desenvolvido como consultor do PNUD (Programa das Naçóes Unidas para o Desenvolvimento), Nova Iorque, Estados Unidos do America.

Waiselfisz, Julio Jacobo (2013), "Mapa da violência 2013. Mortes matadas por armas de fogo", Flacso, Brasil, Brasília, Brasil, <http:// www.mapadaviolencia.org.br/mapa2013_armas.php>, 6 de junho de 2016.

Waiselfisz, Julio Jacobo (2012), "Mapa da violência 2012: os novos padróes da violência homicida no Brasil", Facultad Latinoamericana de Ciencias Sociales Brasil, Brasília, Brasil, <http://www.mapadaviolencia.org.br/mapa2012.php> 7 de junho de 2016.

Wolpin, Kenneth (1978) "An economic analysis of crime and punishment in England and Wales, 1894-1967, Journal of Political Economy, 86 (5), The University of Chicago Press, Chicago, Estados Unidos do America, pp. 815-840.

Wooldridge, Jeffrey (2010), Econometric analysis of cross section and Panel Data, MIT Press, Cambridge, Massachusetts, Estados Unidos do America.

Zaverucha, Jorge (2004), Polícia Civil de Pernambuco: o desafio da reforma, Editora Universitária da Universidade Federal de Pernambuco, Recife, Brasil.

Recibido: 25 de octubre de 2017. Reenviado: 24 de enero de 2018. Aceptado: 13 de febrero de 2018.

Otoniel Rodrigues dos Anjos-Júnior. Doutorado em Economia pela Universidade Federal da Paraíba. Tem interesse nas áreas de Economia do Crime, Economia Regional, Economia Social e Políticas Públicas. Dentre suas últimas publicaçôes, destacam-se: "O rendimento da Castanha de Caju: uma análise espacial para o estado da Paraíba”, Reflexóes Econômicas, 2 (2), Editus-Editora da Universidade Estadual de Santa Cruz, Ilhéus, 
Brasil, pp. 37-54 (2017); "Impacto do Programa mais médicos sobre indicadores de saúde dos Municípios do Estado da Paraíba", Anais do II Encontro de Economia Aplicada de Sergipe, Aracaju, 10-12 de julho, II Encontro de Economia Aplicada de Sergipe (EEA-SE), Brasil, (2017) e "Uma Análise do Trabalho Infantil na Região Sul do Brasil", Anais do 55 Congresso da Sociedade Brasileira de Economia, Administração e Sociologia Rural, Santa Maria, 30 de julho-3 de agosto, Sociedade Brasileira de Economia, Administração e Sociologia Rural, (2017).

Stélio Coêlho Lombardi-Filho: Mestrado em Economia Aplicada pela Universidade Federal da Paraíba (UFPB). Atualmente é aluno do curso de Doutorado em Economia do Centro de Desenvolvimento e Planejamento Regional (CEDEPLAR-UFMG). Integrante do grupo de pesquisa da UFPB intitulado Laboratório de Estudos em Microeconomia Aplicada (LEMA). Tem interesse nas áreas de Economia da Educação, Economia do Trabalho, Avaliação de Políticas Públicas e Métodos Quantitativos Aplicados à Economia. Dentre suas últimas publicaçóes, destacam-se: "Uma Análise do Trabalho Infantil na Região Sul do Brasil", Anais do 55 Congresso da Sociedade Brasileira de Economia, Administração e Sociologia Rural, Santa Maria, 30 de julho-3 de agosto, Sociedade Brasileira de Economia, Administração e Sociologia Rural (2017); "Simulação dos Impactos Econômicos da Proposta Brasileira na COP21: uma abordagem de Equilíbrio Geral Computável"; Anais do 440 Encontro Nacional de Economia, Foz do Iguaçu, entre 13-16 de dezembro, Associação Nacional dos Centros de Pós-Graduação em Economia (2016); "O Impacto da Violência nas Escolas sobre a Proficiência Estudantil: um estudo para as capitais nordestinas", Anais do XVII Seminário sobre a Economia Mineira, Diamantina, 29 de agosto-02 de setembro, Centro de Desenvolvimento e Planejamento Regional, Brasil, (2016).

Pedro Vasconcelos-Maia do Amaral. Doutor em Land Economy pela University of Cambridge. Professor Adjunto da Faculdade de Ciências Econômicas da UFMG e Fellow do Center for Spatial Data Science (University of Chicago). É presidente da Divisáo América Latina da Regional Studies Association (2015-atual) e co-editor dos journals Spatial Economic Analysis (2014-atual) e Regional Studies, Regional Science (2013-atual), membro do Conselho Gestor da Revista Planejamento e Políticas Regionais (2015-atual). Foi secretário adjunto (2015-2017) e secretário executivo (2017) da Associação Nacional de Pós-graduação e Pesquisa em Planejamento Urbano e Regional. Tem experiência na área de Planejamento Regional e Urbano, atuando principalmente na aplicação de métodos de econometria espacial e análise multivariada em estudos 
sobre disparidades regionais e urbanas. Dentre suas últimas publicaçóes, destacam-se: "Distribuição Espacial de Equipamentos de Mamografia no Brasil”, Revista Brasileira de Estudos Urbanos e Regionais, núm. 19, Associação Nacional de Pós-Graduação e Pesquisa em Planejamento Urbano e Regional, São Paulo, Brasil, pp. 326-341 (2017); "Oportunidades no Mercado de Trabalho: uma perspectiva multidimensional e espacial para os municípios brasileiros", Espacios, 38 (3), Editora Espacios, Caracas, Venezuela, pp. 1-11 (2017) e "Medicare Modernization and Diffusion of Endoscopy in FFS Medicare", Health Economics Review, 7 (13), Springer Open, Hannover, Alemanha, pp. 1-9 (2017). 